\title{
DIDÁTICA DO ENSINO SUPERIOR E A LEI 10.639/03 NOS CURSOS DE HISTÓRIA DO CEARÁ
}

\section{DIDACTICS OF HIGHER EDUCATION AND LAW 10.639/03 IN HISTORY COURSES OF CEARÁ}

\author{
Joselina da Silva ${ }^{1}$ \\ Ângela Maria Bessa Linhares ${ }^{2}$ \\ Adriano Ferreira de Paulo 3
}

\begin{abstract}
RESUMO: A Lei 10.639/03 foi instituída há 16 anos, inserindo estudos sobre História e cultura africana e afro-brasileira, modificando a Lei de Diretrizes e Bases da Educação no Brasil em todos os níveis de ensino, inclusive o superior. Para a aplicação desta lei, os ensinos de História, Literatura e Educação Artística estão na vanguarda das didáticas a serem apresentadas. Neste trabalho, vamos expor os dados de uma pesquisa realizada sobre a formação de professores de História nas duas maiores universidades públicas do Ceará, UFC e UECE, visando analisar como o ensino superior tem se adequado ao que pede a Lei 10.639/03 e, também, propor as componentes curriculares em torno de Didática do Ensino Superior como possibilidade de aplicação da referida lei. Esta pesquisa é do tipo qualitativa, e tem como procedimentos metodológicos análises bibliográficas e documentais. Nossa fundamentação teórica está embasada em alguns autores como Alberti (2013), Candau (2000), Fischer (2009), Gomes (2017), Munanga (2005), Saviani (2003). Os resultados encontrados mostram um diferencial entre o escrito em seus Projetos Políticos e Pedagógicos e a oferta de componentes curriculares em suas grades semestrais, sendo que a UFC contempla, em sua grade curricular, abordagens sobre a Lei $10.639 / 03$, enquanto que a UECE apresenta duas realidades distintas
\end{abstract}

\footnotetext{
${ }^{1}$ Professora de mestrado e doutorado no Programa de Pós-graduação em Educação da Universidade Federal do Ceará (UFC) e do Programa de Pós-Graduação em Educação da Universidade Federal Rural do Rio de Janeiro (UFRRJ). Pós doutoranda pela Pontifícia Universidade Católica do Peru (PUCP). E-mail: joselinajo@yahoo.com.br

2Professora titular da Universidade Federal do Ceará (UFC), assessora pedagógica da Associação de Corais Infantis Um Canto Em Cada Canto; participa como docente do Mestrado em Saúde Pública da Faculdade de Medicina da UFC e é membro da Articulação Nacional de Educação Popular Em Saúde e do conselho consultivo do Instituto Terramar. E-mail: angela.ciranda@hotmail.com

${ }^{3}$ Doutorando e mestre em Educação Brasileira pelo Programa de Pós-Graduação em Educação da Universidade Federal do Ceará (UFC), linha de Movimentos Sociais, Educação Popular e Escola. Bolsista Capes. E-mail: acanibalia@gmail.com
}

História \& Ensino, Londrina, v. 25, n. 02, p. 35-57, jul./dez. 2019 
entre seus campi do interior e da capital do Ceará, pois os primeiros atendem de maneira adequada à legislação, enquanto que o curso de Fortaleza apresenta necessidades urgentes de implementação à temática de cultura africana e afrobrasileira para seus futuros historiadores. As aulas referentes às didáticas para o ensino superior, contudo, mostram-se como uma possibilidade de inserção estratégica para as diretrizes legais. Com isso, concluímos que se faz necessária uma adequação efetiva, iniciando pelos registros formais nos Projetos Políticos e Pedagógicos de ambas universidades, como, também, um maior investimento em aulas que contemplem cultura afro-brasileira e africana no Ensino de História.

Palavras-chave: Lei 10.639/03; Didática. História.

\begin{abstract}
Law 10.639 / 03 was instituted 16 years ago, inserting studies on African and Afro-Brazilian history and culture, modifying the Law of Guidelines and bases of Education in Brazil at all levels of education, including the higher level. To apply this law, the teaching of History, Literature and Artistic Education are in the forefront of the didactics presented. In this work, we will present the data of a research carried out on the formation of History teachers in the two largest public universities of Ceará, UFC and UECE, aiming to analyze how higher education has adapted to what is required by law 10.639 / 03, and also propose the curricular components around Didactics of Higher Education as a possibility of application of said law. This research is qualitative, and its methodological procedures are bibliographical and documentary analyzes. Our theoretical foundations are based on some authors such as Alberti (2013), Candau (2000), Fischer (2009), Gomes (2017), Munanga (2005) and Saviani (2003). The results show differences between what is written on the Political and Pedagogical Projects and the offer of curricular components in the semester grades. UFC contemplates, in its curricular framework, approaches to law 10.639 / 03, while UECE presents two realities between the interior and capital cities of Ceará. The first ones attend adequately to the legislation, while the Fortaleza course presents urgent needs to implement African and Afro-Brazilian culture for its future historians. However, the lessons related to didactics for higher education show a possibility of strategic insertion into the legal guidelines.With this, we conclude that an effective adaptation is necessary, beginning with the formal records in the Political and Pedagogical Projects of both universities, as well as greater investments in classes that contemplate AfroBrazilian and African culture in History teaching.
\end{abstract}

Keywords: Law 10.639 / 03; Didactics; History.

\title{
Introdução
}

O Ensino de História africana e cultura afro-brasileira e indígena, que é obrigatório em todos os níveis da Educação Básica pública e particular no Brasil, é um tema que acumula décadas em articulações e possibilidades de aplicação efetiva no sistema educacional brasileiro. Sua institucionalização, e consequente obrigatoriedade, aconteceu através da Lei no 10.639/03, 
busca oportunizar o "direito dos descendentes de africanos, assim como de todos os cidadãos brasileiros, à "valorização de sua identidade étnicohistórico-cultural" (SILVA, 2005, p. 156).

A Lei 10.639, de 09 de janeiro de 2003, trouxe importante modificação para a LDB (Lei de Diretrizes e Bases da Educação), também conhecida como Lei 9.394/06 (BRASIL, 1996), alterando alguns de seus artigos (26-A e 79-B), trazendo a citada obrigatoriedade e a inserção, nos componentes curriculares de Educação Artística, Literatura e História, de estudos sobre História e Cultura africana e afro-brasileira, abrangendo temáticas como as lutas históricas dos povos africanos no Brasil, suas culturas, contribuições intelectuais, participação na formação da sociedade nacional, como, também, na econômica e política ${ }^{4}$.

Em nível estadual, a Secretaria de Educação do Ceará também se posicionou sobre o assunto, com a Resolução No 416/2006 que regulamenta - Ensino da História e Cultura Afro-Brasileira e Africanas e dá outras providências, recomendando que as universidades incluíssem em seus currículos os assuntos que envolvem a Lei 10639/03.

Art. 10 - Às instituições de ensino, em todos os níveis e modalidades da educação básica e, em especial, às que desenvolvem programas de formação inicial e continuada de professores, incumbe adotar as normas contidas nesta Resolução para o cumprimento das Diretrizes Curriculares para a Educação das Relações Étnico-Raciais e para o Ensino da História e Cultura Afro-Brasileira e Africana (CEARÁ, 2006, p. 2).

É válido informar, ainda, que no ano de 2008 aconteceu uma nova modificação na LDB, onde a Lei $10.639 / 03$ passou a ser reconhecida como Lei $11.645 / 08$, trazendo como novidade referências às diversas etnias indígenas, com as mesmas considerações das populações negras.

4 § 20 Os conteúdos referentes à História e Cultura Afro-Brasileira serão ministrados no âmbito de todo o currículo escolar, em especial nas áreas de Educação Artística e de Literatura e História Brasileiras (BRASIL, 2003). 
Entretanto, neste artigo enfocaremos como referencial a legislação de 2003, tendo em vista as questões de cunho culturais aqui em destaque.

$\S 1$ ㅇ O conteúdo programático a que se refere este artigo incluirá diversos aspectos da história e da cultura que caracterizam a formação da população brasileira, a partir desses dois grupos étnicos, tais como o estudo da história da África e dos africanos, a luta dos negros e dos povos indígenas no Brasil, a cultura negra e indígena brasileira e o negro e o índio na formação da sociedade nacional, resgatando as suas contribuições nas áreas social, econômica e política, pertinentes à história do Brasil (BRASIL, 2008).

Apesar de ser uma lei que completou 16 anos em 2019, os parâmetros estabelecidos pelo texto da 10.639/03 foram analisados em 2017 pela relatora da comissão de implementação, a professora Petronilha Gonçalves e Silva, constatando que os estudos sobre História e cultura africana e a afro-brasileira são negligenciados em várias instituições de ensino pelo Brasil.

Existe um estudo do Ministério da Educação [MEC], solicitado pela Unesco e feita em todas as regiões do país. A pesquisa foi coordenada pela professora Nilma Limo Gomes, da Universidade Federal de Minas Gerais [UFMG], e mostra - e é também o que eu tenho observado - que aumentou consideravelmente o número de professores, negros e nãonegros, preocupados com a educação das relações étnicosraciais. Entretanto, ainda continua dependendo de uma iniciativa individual do professor ou de um grupo de professores. É raro, difícil que essa seja uma política das escolas, e que esta [disciplina] conste no plano políticopedagógico das instituições (SILVA, 2017).

Estas negligências apresentam-se nas três esferas de ensino: fundamental, médio e superior, sendo que nossa escritura terá a atenção voltada para este último nível, especificamente no curso de Licenciatura em História, uma vez que esta componente curricular, juntamente com Educação Artística e Literatura, estão na "vanguarda" para disseminar estudos sobre a valorização da História e Cultura africana e afro-brasileira. 
É importante frisar, porém, que não apenas as três disciplinas destacadas devem se debruçar sobre os estudos afro-brasileiros, sendo crucial que haja uma transversalidade nas componentes curriculares da Educação Básica.

Assim sendo, havendo uma intimidade desde sua formação inicial dos futuros historiadores com as temáticas que envolvem a Lei 10.639/03, os professores terão maior suporte para desenvolver os temas em seu ambiente de trabalho, apresentando capital cultural básico para o trato com diversas questões que envolvem estas temáticas.

Nesta pesquisa, enfocaremos considerações sobre a formação de professores nos Cursos de Licenciatura em História, a partir dos componentes curriculares referentes à Didática no Ensino Superior, buscando uma perspectiva para a aplicação da Lei 10.639/03, compreendendo que as discussões que podem ser desenvolvidas vão além da sala de aula, tangenciando resignificações políticas e sociais para alunos, professores e a comunidade escolar. Ao redimensionar a importância dos povos africanos e sua cultura na formação do povo brasileiro, consequentemente são realizadas problematizações variadas nos conteúdos de História, pois

Não se trata apenas de trazer para dentro da escola um novo componente curricular, mas uma temática e um debate marcados por uma longa trajetória de disputas e embates, de polêmicas e dissensos, e também de silenciamentos. (ALBERTI, 2013, p. 59).

Quando a redação da lei aqui analisada se refere ao termo "obrigatório"5, entendemos que após 16 anos de sua implementação, ocorrida em janeiro de 2018, seria possível perceber um certo amadurecimento dos processos iniciados em 2003, principalmente no tocante à formação de professores, especificamente nesta análise, aqueles

\footnotetext{
${ }^{5}$ Art. 26-A. Nos estabelecimentos de ensino fundamental e médio, oficiais e particulares, torna-se obrigatório o ensino sobre História e Cultura Afro Brasileira (BRASIL, 2003).
} 
dedicados ao Ensino de História. Neste entendimento, observaremos a incorporação da Lei 10.639/03 nos cursos de Licenciatura Plena em História de duas grandes universidades públicas do Ceará: a Universidade Estadual do Ceará (UECE) e a Universidade Federal do Ceará (UFC). Além dessa observação, pretendemos, ainda, contribuir com apontamentos pertinentes para os componentes curriculares referentes às teorias de Didática no Ensino Superior, no sentido de gerar possibilidades de envolvimento de temáticas afro-brasileiras na formação dos futuros historiadores.

Este trabalho está dividido em três partes: na primeira, trataremos sobre a descrição metodológica da pesquisa; em seguida, investigaremos os Projetos Políticos e Pedagógicos (PPP) da UECE e da UFC, dos cursos de Licenciatura em História, a fim de verificarmos as considerações para a formação destes professores em consonância com a Lei 10.639/03; e, por fim, discorreremos sobre contribuições para os componentes curriculares em torno dos temas de Didática no Ensino Superior conectando temas históricos e afro-brasileiros.

\section{Descrição metodológica}

Nesta pesquisa trazemos informações não limitadas a dados quantitativos, buscando compreender as subjetividades dos sujeitos envolvidos nesta investigação, sendo adequada a utilização da pesquisa de caráter qualitativo. Este tipo de pesquisa se destaca por ser aquela que "não se preocupa com representatividade numérica, mas sim com o aprofundamento da compreensão de um grupo social, de uma organização" (CÓRDOVA; SILVEIRA, p. 31, 2009).

Quanto à sua aplicação, a pesquisa qualitativa é compreendida também como um apuro de sensibilidades. Existe ainda o entendimento de que ela se comporta como um prolongamento do pesquisador, que insere suas subjetividades analíticas para alcançar uma compreensão verídica do objeto pesquisado. 
Os procedimentos metodológicos estão centrados em análises bibliográficas e documentais, onde nas primeiras o enfoque está na aplicação da Lei 10.639/03 e em conceitos sobre didática no ensino superior, com autores como Alberti (2013), Candau (2000), Fischer (2009), Martins (2011), Parriras (2017), Saviani (2003), Veiga (2008). O uso da bibliografia contribui na produção científica do discurso aqui apresentado, fundindo variadas concepções, como pode ser verificado que:

Ao tratar da pesquisa bibliográfica, é importante destacar que ela é sempre realizada para fundamentar teoricamente $o$ objeto de estudo, contribuindo com elementos que subsidiam a análise futura dos dados obtidos. Portanto, difere da revisão bibliográfica, uma vez que vai além da simples observação de dados contidos nas fontes pesquisadas, pois imprime sobre eles a teoria, a compreensão crítica do significado neles existente (LIMA; MIOTO, 2007, p. 44).

Sobre a parte documental, o foco está em fontes primárias digitalizadas como: as Leis 10.639/2003, 11.645/2008, CNE/CP no 01/2004, que institui as Diretrizes Curriculares Nacionais para a Educação das Relações Étnico-Raciais e para o Ensino de História e Cultura AfroBrasileira e Africana; o Parecer do Conselho Nacional de Educação - Câmera Plena (CNE/CP) no 03/2004, referente às Diretrizes Curriculares Nacionais para a Educação das Relações Étnico-Raciais e para o Ensino de História e Cultura Afro-Brasileira e Africana; o Plano Nacional de Implementação das Diretrizes Curriculares Nacionais para Educação das Relações Étnico-Raciais e para o ensino de História e Cultura Afro-Brasileira e Africana (2009); a Resolução No. 416/2006 do Conselho Estadual de Educação do Ceará (2006); e, ainda, os Projetos Político e Pedagógicos (PPP), como também as grades curriculares dos cursos de Licenciatura Plena em História da Universidade Federal do Ceará e da Universidade Estadual do Ceará.

Ao fazermos a junção das fontes bibliográficas e documentais, temos uma configuração de estratégias para a escrita deste trabalho utilizadas por historiadores, o que nos interessa até mesmo pelo foco nos componentes curriculares analisados, onde "montar, combinar, compor, cruzar, revelar o 
detalhe, dar relevância ao secundário, eis o segredo de um método do qual a História se vale, para atingir os sentidos partilhados homens de um tempo ao outro" (PESAVENTO, 2003, p. 65).

\section{Formação de professores de História e a Lei 10.639/03 no Ensino Superior}

Para a análise da relação entre a formação dos futuros professores de História da UECE e da UFC com os temas abordados pela Lei 10.639/03, analisamos os PPPs e as Grades Curriculares propostas para cada curso, ensejando identificar como os formandos estão sendo constituídos em seu capital cultural sobre História e cultura africana e afro-brasileira.

Iniciando pela Universidade Estadual do Ceará, verificamos que o PPP em vigência é um documento unificado entre todos os Cursos de Licenciatura Plena em História desta universidade, denominado como Projeto Político Pedagógico Curso de Licenciatura em História. Ele é constituído da agregação dos campus da cidade de Fortaleza, capital do estado do Ceará, identificado como o próprio nome da universidade, UECE e, ainda, por dois campi do interior do estado, sendo o primeiro deles o campus da região do Sertão Central do Ceará, denominado de Faculdade de Educação, Ciências e Letras do Sertão Central (FECLESC) ${ }^{6}$ e, ainda, pelo campus da cidade de Limoeiro do Norte, reconhecido como Faculdade de Filosofia Dom Aureliano Matos (FAFIDAM) ${ }^{7}$. O PPP analisado é datado de 2006, sendo estruturado desde o ano de 2001 com reuniões entre

${ }^{6}$ A Faculdade de Educação, Ciências e Letras do Sertão Central - FECLESC foi criada em 1976, sendo resultado de lutas e mobilização da sociedade quixadaense e do Sertão Central. Em 1983, passou a fazer parte da Universidade Estadual do Ceará - UECE, que implantou os cursos de Pedagogia, Ciências e História. Em 1988 esses cursos foram reconhecidos pelo Conselho Federal de Educação, ficando como cerne desta instituição a formação de profissionais da educação. (UECE, 2018a).

7 A Faculdade de Filosofia Dom Aureliano Matos (FAFIDAM) foi criada em 19 de agosto de 1966, através da Lei n. 8.557. Foi estruturada como Autarquia Estadual em janeiro de 1967, pela da Lei no. 8.716 e possuía autonomia administrativa, financeira, pedagógica e disciplinar, comum a outras instituições de ensino superior à época, no Ceará, como a Faculdade de Filosofia do Ceará, a Escola de Administração e a Escola de Veterinária do Ceará. (UECE, 2018b). 
profissionais dos três campi da UECE. Observando sua descrição dos componentes curriculares propostos para os quatro anos e meio de duração dos cursos (campus da capital) e de quatro anos (campus do interior), a única referência que ele possui, sobre África ou temas correlatos, está disposta na componente curricular sobre História Contemporânea III.

\begin{abstract}
HISTÓRIA CONTEMPORÂNEA III (DO PÓS-1945 AO TEMPO PRESENTE) (Pré-requisito História Contemporânea II) Experiências socialistas no século $X X$; Socialdemocracia e stalinismo; Descolonização na África e Ásia; Arte e cultura no pós-guerra; Crise capitalista dos anos 70; Estado, sociedade e trabalho pós-1970; O colapso do socialismo no Leste europeu e na URSS; Estado Nacional e nacionalismo no século $X X$; Oriente e Orientalismo no século $X X ; A$ questão dos Bálcãs e as guerras imperiais na década de 90 ; A nova dinâmica Mundial no pós-guerra fria (UECE, 2006, p. 33).
\end{abstract}

Sabemos que os estudos sobre História Contemporânea não abarcam a contento o que pede a Lei 10.639/03, visto haver um conjunto de estudos a serem explorados, bem como a necessidade de mais especificidades para serem dedicadas às africanidades pedidas. A elaboração desta fonte chama atenção por ter sido criada entre os anos de 2001 e 2006, ou seja, passando pela instituição da lei e seu desdobramento nas Diretrizes Curriculares 01/2004, que estabelecem no $\S 1^{\circ}$ que "As Instituições de Ensino Superior incluirão nos conteúdos de disciplinas e atividades curriculares dos cursos que ministram, a Educação das Relações ÉtnicoRaciais, bem como o tratamento de questões e temáticas que dizem respeito aos afrodescendentes" (BRASIL, 2004a, p. 1).

Observando a definição dada ao componente curricular chamado Didática do Ensino de História, podemos perceber a ausência dos temas propostos em 2003 para as questões acerca da História e cultura afrobrasileira, cabendo ao professor um engajamento sobre a Lei 10.639/03 para acontecer a presença deste assunto.

Didática do Ensino de História: arte e técnica. O conhecimento histórico e os procedimentos didáticos do 
ensino de história. Pressupostos da constituição da Didática do Ensino de História. Proposições sócio-históricas e pedagógicas do Ensino de História. Histórico das finalidades formativas do ensino de história. Parâmetros teóricometodológicos e pedagógicos da organização curricular de História. A didática na formação do profissional de História (UECE, 2006, p. 29).

Como pode ser observado, o que fica descrito como ementa para a componente curricular dificulta a possibilidade direta para que haja a presença da Lei 10.639/03 na formação dos discentes da UECE, deixando apenas brechas para algum possível interesse, considerando ainda a variável de que o professor seja engajado nesta causa. Porém, como poderia "surgir" o interesse, tanto em professores como alunos, sem o estímulo a conteúdos que remetam a debates acerca da História e cultura afro-brasileira?

Quanto à análise das grades curriculares dos cursos, é possível perceber que acontece uma divisão de interesses sobre os conteúdos em torno da Lei 10.639/03 que vai além dos textos do PPP. A grade curricular do Curso de História do campus Fortaleza, fluxo de 2016.2, não possui nenhum componente curricular que envolva a referida lei, colocando este custo à margem das diretrizes curriculares e o tornando credor, em conteúdo, das grades dos dois campi do interior do estado. No caso da FAFIDAM, grade curricular fluxo 2013.1, existe a componente de código LM122 História da Cultura Afro-Brasileira, de caráter optativo. Por fim, a grade de fluxo 2016.2 da FECLESC, registra quatro componentes distintas, todas também de caráter optativo, com seus respectivos códigos: QX 979 História da África I (terceiro semestre); QD 016 História da África 2 (oitavo semestre); QD 012 História e Cultura Indígena e Afro-Brasileira (oitavo semestre); e, por fim, o código QD 013 História Indígena (semestre em aberto).

Numa comparação entre os cursos de História da capital e do interior, veremos pela descrição em tela, que o compromisso dos campi do interior tem a preocupação de estar dentro da legislatura educacional vigente, 
chegando a demonstrações de grande engajamento nesta causa como é o caso da FECLESC. Apesar de todas as componentes curriculares que se relacionam com as Leis $10.639 / 03$ ou $11.645 / 08$, tanto de Limoeiro do Norte, como do Sertão Central serem optativas, podemos contar como respeito à legislação e diferencial no capital cultural dos futuros historiadores em sala de aula.

No caso da UFC, o PPP de Licenciatura em História em vigência é de agosto de 2010, e apresenta conformidade com a lei instituída, sendo observado que os componentes curriculares de História Contemporânea II e História da África inserem dentro do curso referências à proposta da Lei 10.639/03, como pode ser observado:

\begin{abstract}
HI005-HISTÓRIA CONTEMPORÂNEA II - O mundo da expansão colonialista européia e norte-americana e dos novos impérios coloniais. As grandes migrações. Movimentos e organizações dos trabalhadores. O Primeiro Conflito Mundial. Revoluções na Rússia e processos revolucionários internacionais. Crise do capitalismo no período entre-guerras. Movimentos e Estados autoritários e totalitários. O Segundo Conflito Mundial. O mundo durante o bipolarismo e o conflito ideológico. Descolonização e revoluções na África e na Ásia. Crise do mundo socialista. Unificação da Europa e multietnicidade. Conflitos nacionais e étnicos. A questão do meio-ambiente. Mudanças culturais do fim do séc. XIX à era da mídia e da informática. O mundo durante a nova globalização do capitalismo. HIO04 - HISTÓRIA DA ÁFRICA Fontes, metodologias e fundamentos para o estudo da história da África; a África pré-colonial; a diversidade étnica; a expansão islâmica; os principais reinos da África ocidental na véspera e durante a expansão marítima europeia; a inserção africana no mercado mundial do século XVI; os séculos do tráfico negreiro; o Atlântico Negro; o imperialismo e a partilha da África no século XIX (UFC, 2010, p. 24).
\end{abstract}

Se considerarmos a grade curricular mais recente, fluxo de 2013.1, veremos que mais um componente curricular foi agregando, o HI 0139, que discorre sobre História da África na Contemporaneidade (sexto semestre), de caráter optativo. O curso apresenta ainda uma atividade de extensão voltada para a questão da História e cultura africana e afro-brasileira, a Mostra Internacional de Cinema Africano, atividade desenvolvida pelo 
professor Franck Pierre Gilbert Ribard, em parceria com a Universidade da Integração Internacional da Lusofonia Afro-Brasileira (UNILAB).

O interesse da UFC em abordar a Lei 10.639/03 em seu curso de História, desde componentes curriculares até atividades de extensão e parcerias com outras instituições, reforça a possibilidade de múltiplos recursos que os formandos possam ter para desenvolverem variadas explorações temáticas, ressignificando a imagem da História e cultura africana e afro-brasileira, como orientam as Diretrizes Curriculares 03/04:

O ensino de História e Cultura Afro-Brasileira e Africana se fará por diferentes meios, em atividades curriculares ou não, em que: se explicitem,busquem compreender e interpretar, na perspectiva de quem o formule, diferentes formas de expressão e de organização de raciocínios e pensamentos de raiz da cultura africana; -promovam-se oportunidades de diálogo em que se conheçam, se ponham em comunicação diferentes sistemas simbólicos e estruturas conceituais, bem como se busquem formas de convivência respeitosa, além da construção de projeto de sociedade em que todos se sintam encorajados a expor, defender sua especificidade étnico-racial e a buscar garantias para que todos o façam;sejam incentivadas atividades em que pessoas - estudantes, professores, servidores, integrantes da comunidade externa aos estabelecimentos de ensino- de diferentes culturas interatuem e se interpretem reciprocamente, respeitando os valores, visões de mundo, raciocínios e pensamentos de cada um (BRASIL, 2004b, p. 11).

Apesar das divergências entre ter ou não disciplinas que explorem questões sobre História da África e cultura afro-brasileira, sobre serem ou não obrigatórias e, ainda, a existência de atividades de extensão na formação dos historiadores das duas maiores instituições públicas de ensino superior do estado do Ceará, uma componente curricular se faz presente em todos os campi: Didática do Ensino de História. Nestes estudos, em alguns de seus conceitos centrais, o professor pode encontrar uma abertura, de modo transversal, para considerar os temas sobre História da África e cultura afro-brasileira com reflexões profícuas.

No campo da didática, podem ser realizadas abordagens em alinhamento com a Lei 10.63903 , podendo trazer benefícios aos discentes 
de Licenciatura em História em seus futuros trabalhos em sala de aula, principalmente possibilitando que o professor venha a ser aquele que deve "ressaltar a legitimidade de um trabalho pedagógico que busca valorizar a diversidade sociocultural brasileira e desenvolver estratégias variadas de enfrentamento de desigualdade historicamente perpetuadas em nossa sociedade" (SANTOS, 2013, p. 83).

Seguindo nossa análise, iremos discorrer sobre as contribuições que o ensino de Didática, no Ensino Superior de História, pode contribuir para a formação de seus profissionais conectados com a valorização da História e cultura afro-brasileira.

\section{Contribuições didáticas no Ensino Superior: História e Culturas afro-brasileira}

Observando o PPP de ambas universidades, os componentes curriculares destinados à Didática do Ensino de História se constituem de temas que permitem a inserção do manejo com os interesses da Lei 10.639/03. Faremos nossas contribuições para didáticas no ensino superior, a partir delas. Para nossas proposições, destacaremos um item dentro dos conteúdos a serem abordados nos componentes sobre didática de cada instituição, a partir do entendimento de que, através deles, é possível o enlace com os estudos sobre História e cultura afro-brasileira. Inicialmente dentro do item Proposições sócio-históricas e pedagógicas do Ensino de História, para as aulas de Didática do Ensino de História: arte e técnica, na UECE, como também nos estudos que discorrem sobre Multiculturalismo e políticas educacionais de ação afirmativa para o ensino de Estudos SócioHistóricos e Culturais da Educação na UFC.

\subsection{Proposições sócio-históricas e pedagógicas do Ensino de História}


Nossa contribuição para a Didática do Ensino de História da UECE ocorrerá com a sugestão de dois temas: primeiro, a identificação do modelo pedagógico que melhor abarca a legislação aqui explicitada e, também, a necessidade de intervenção do professor para as temáticas de relações étnico-raciais na escola.

Inicialmente, é necessário que o estudante de História identifique que os estudos da História e cultura afro-brasileira, nos parâmetros da Lei 10.639/03 e das Diretrizes Curriculares que the fundamentam, se enquadram numa pedagogia progressista, do tipo histórico-crítica, pois esta é a que responde à necessidade de encontrar, dentro da Educação, alternativas de resistência à pedagogia dominante, possibilitando o desenvolvimento de análises críticas da Educação (SAVIANI, 2003, p. 133).

Esta identificação é importante, pois possibilita ao futuro professor de História compreender que as intenções da Lei 10.639/03 também objetivam rasurar os discursos que colocam a cultura afro-brasileira em segundo plano na formação do Brasil, retirando-Ihe toda a carga de influências sociais e econômicas, deixando-Ihe ao sabor de folclorizações estigmatizadas, como o canto e dança, e manifestações tidas como exóticas, por exemplo, as religiosas. Uma vez rasuradas as certezas, o aluno é colocado diante de questionamentos, dúvidas, para a constituição de um novo conhecimento. $O$ importante são as dúvidas, as perguntas que vão levar à sistematização que deram origem ao conhecimento. O que mais se destaca numa pedagogia progressista é o aluno, é entender a origem do conhecimento e a pertinência dele para a profissão e para a sociedade. Os alunos não podem ser destituídos do principal.

Tomando como auxílio essas dúvidas, para penetrar em temas histórico-culturais afrodescendentes, o professor adepto da pedagogia histórico-crítica alia-se à Lei 10.639/03 ao buscar "promover a socialização dos conhecimentos representativos das máximas conquistas científicas e culturais da humanidade, por meio da prática pedagógica, tornando a realidade inteligível" (MARTINS, 2011, p. 54). 
Em detalhamento aos assuntos que devem ser postos em prática na sala de aula, o professor de História tem seu ponto chave no Ensino Fundamental, nas aulas de $6^{\circ}$. ano, quando é apresentado o Antigo Egito e, na sequência, o 7o. ano apresenta outra grande possibilidade, nos temas que fazem transição da Idade Média para a Idade Moderna, iniciando pelas grandes navegações, a chegada dos portugueses no Novo Mundo e quando os africanos foram trazidos à força, por meio da escravidão, para terras brasileiras, resignificando o que foi a participação destes variados povos na formação do país, atendendo de modo satisfatório as Diretrizes Curriculares 03/04:

\begin{abstract}
Em outras palavras, aos estabelecimentos de ensino está sendo atribuída responsabilidade de acabar com o modo falso e reduzido de tratar a contribuição dos africanos escravizados e de seus descendentes para a construção da nação brasileira; de fiscalizar para que, no seu interior, os alunos negros deixem de sofrer os primeiros e continuados atos de racismo de que são vítimas. Sem dúvida, assumir estas responsabilidades implica compromisso com o entorno sociocultural da escola, da comunidade onde esta se encontra e a que serve, compromisso com a formação de cidadãos atuantes e democráticos, capazes de compreender as relações sociais e étnico-raciais de que participam e ajudam a manter e/ou a reelaborar, capazes de decodificar palavras, fatos e situações a partir de diferentes perspectivas, de desempenhar-se em áreas de competências que lhes permitam continuar e aprofundar estudos em diferentes níveis de formação (BRASIL, 2004b, p. 17).
\end{abstract}

Na sequência propositiva, vemos a necessidade de intervenção do professor na realidade que circunda a escola. Dentre os critérios de uma pedagogia progressista, o educador observa e se insere na realidade da qual participará, não cabendo mais a figura do profissional dotado de conhecimento que vai inserir na mente dos alunos "a verdade", principalmente em temas sobre História e cultura afro-brasileira.

Rejeita-se a concepção tradicionalmente aceita que entende ensinar como "transmitir conhecimento", ou que compreende conhecimento como algo acabado, produto definitivamente 
pronto, esperando apenas ser transmitido de alguém que

"sabe" para quem "não sabe" (FISCHER, 2009, p. 312).

A constituição de uma nova ideia sobre os africanos, sua História e cultura, bem como sua influência sobre a formação da sociedade brasileira, com questionamentos e reflexões dos próprios alunos, mediante experiências e debates, pode ser de grande utilidade para a inserção do professor na realidade concreta dos alunos. Esses debates, inclusive, passam por temas intrínsecos à Lei 10.639/03, tornando-se em assuntos inescapáveis ao professor, possibilitando uma abertura para aulas mais participativas. Assim, se o professor não abrir o olho para a realidade em que está inserido, pode se tornar um robô, sendo aquele docente que já está programado, repetitivo, tornando a aula monótona, tanto para ele como para os alunos.

\subsection{Multiculturalismo e políticas educacionais de ação afirmativa}

Com o avanço no atendimento à Lei $10.639 / 03$ na UFC, como detalhado anteriormente, nossa contribuição para a Didática do Ensino de História nesta instituição será feita observando dois pontos: o tipo de multiculturalismo a ser abordado no currículo de ensino e, ainda, observações sobre o planejamento na abordagem de temas históricoculturais afro-brasileiros, uma vez verificadas as pautas deste componente curricular como descrito no PPP do curso.

ESTUDOS SÓCIO-HISTÓRICOS E CULTURAIS DA EDUCAÇÃO: Conceitos fundamentais à Sociologia, História e Antropologia pra a compreensão da relação entre Educação e Sociedade. A interdisciplinaridade do pensamento pedagógico. Multiculturalismo e políticas educacionais de ação afirmativa (UFC, 2010, p.30).

Partindo dos estudos de Vera Maria Candau sobre relativismo e universalismo na estruturação de currículos de ensino, evidenciamos que entre as complexidades apresentadas pela autora, o universalismo aberto, 
tolerante e inter-multicultural, abrange as contribuições que se pretende nas possibilidades temáticas aqui apresentadas. Ainda que os argumentos da autora sejam anteriores à instituição da Lei 10.639/03 vemos, em sua tessitura teórica, o vislumbre das ações afirmativas que viriam em poucos anos na Educação, modificando a LDB.

As posições mais universalistas e aquelas mais sensíveis à problemática da diversidade cultural se têm explicitado claramente. Convém também salientar que, pela primeira vez em nosso país, uma proposta curricular de caráter nacional inclui, neste caso na categoria de "tema transversal", a temática da diversidade cultural (CANDAU, 2000 , p. 80).

O professor, neste sentido intercultural, deve buscar possibilidades de entendimento onde variadas culturas possam conviver, interagir e estabelecer um diálogo respeitoso que preze pela diversidade das suas manifestações, principalmente para fins desta escritura, as afro-brasileiras.

Firmada a interculturalidade, o passo seguinte acontecerá por meio dos planejamentos de aula do professor, tendo como objetivo precípuo a inserção do aluno concreto, real, negros e não negros, a fim de serem participantes ativos nos temas da Lei $10.639 / 03$, para que ocorram interações de diferenças na constituição de experiências cotidianas. Neste ponto, é então desejada a tomada de consciência crítica dentro da comunidade escolar no amplo sentido de relações étnico-raciais. O professor, em um primeiro momento, só conhece a legislação e a ciência, mas precisa conhecer o aluno concreto, real, conjuntamente. Quem vai trazer a grande ênfase para o planejamento do professor é o aluno, caso contrário ele fica sem esse tripé necessário.

Para ser possível a formação do tripé legislação, ciência e aluno, é necessária uma modificação constante, analítica do professor desempenhando seu papel no espaço escolar. Isso ocorre quando o profissional está disposto a modificar suas rotinas de ações pedagógicas, procedimentos didáticos, questionando seus próprios saberes, discutindo a 
descontextualização e o aligeiramento do ensino e ainda questionando o esquema dissociativo da relação entre teoria e prática (VEIGA, 2008, p. 269).

$\mathrm{Na}$ perspectiva do planejamento entre uma pedagogia mais tradicional e uma progressista, carece que o professor esteja no meio termo: ter um planejamento sofisticado, completo, constantemente atualizado e, também, propício a dar oportunidades para os alunos participarem, porque quando se faz isso, ele será surpreendido dado envolvimento dos alunos que trazem muito mais do que o professor poderia supor. Neste entendimento, é primordial o debruçar dos professores em questões centrais sobre História e cultura afro-brasileira na Educação, a necessidade de revisão de conteúdo, atitudes, estruturas, e da própria epistemologia desse saber. É necessário, por exemplo, pensar como os autores afro-brasileiros e africanos são introduzidos, se existe uma dinâmica que compreenda o efeito da escravidão e diáspora como fundadores de problemas atuais, se a perspectiva rompe com o eurocentrismo naturalizado na ideia de História Universal, entre outras possibilidades, como bem analisou Cíntia Santos Diallo (2017, p. 236), pesquisando sobre currículos e disciplinas de Licenciatura em História.

Um ponto relevante é compreender que a História da África como disciplina acadêmica nasce nas lutas anticoloniais e antirracistas empreendidas no continente africano e como mecanismo de (re) elaboração da identidade africana negada pelo colonialismo. 'Penso que, no Brasil, a disciplina deve assumir papel muito parecido, ao se estabelecer como instrumento de combate ao racismo, de promoção de igualdade racial e da (re) construção da identidade dos afrobrasileiros.

Neste planejamento, não cabem fragilidades ao lidar com estas questões, principalmente pelo avanço da quantidade de alunos e alunas negras ingressando nas universidades, a partir de ações afirmativas que trazem consigo "uma outra corporeidade acompanhada de uma produção de 
outras experiências e significados" (GOMES, 2017, p.115). Essa visão é confirmada pela Resolução CNE/CP no 03/2004:

\begin{abstract}
Para obter êxito, a escola e seus professores não podem improvisar. Têm que desfazer mentalidade racista e discriminadora secular, superando o etnocentrismo europeu, reestruturando relações étnico-raciais e sociais, desalienando processos pedagógicos. Isto não pode ficar reduzido a palavras e a raciocínios desvinculados da experiência de ser inferiorizados vivida pelos negros, tampouco das baixas classificações que lhe são atribuídas nas escalas de desigualdades sociais, econômicas, educativas e políticas (BRASIL, 2004b, p. 6).
\end{abstract}

Para uma organização didática na abordagem de temas históricoculturais afro-brasileiros, então, é fundamental que os objetivos geral e específicos, a serem definidos, possam obter como resultados "atitudes, convicções e valores que se devem desenvolver em relação ao relacionamento humano, à realidade social (atitude científica, consciência crítica, responsabilidade, solidariedade, etc)", de acordo com Parreiras (2017). Desta forma, a escola possibilita a constituição de uma memória coletiva, local, ancestral, para negros e não negros, conforme Munanga (2005), onde a identificação de um pertencimento racial colabora em desfazer mentalidades de preconceito racial.

\title{
Considerações finais
}

Entendemos que se faz necessário um aprofundamento maior por parte dos professores em formação, e mesmo os responsáveis por disciplinas em nível superior, nas causas que envolvem a Lei 10.639/03, a fim de se tornarem agentes no cumprimento da Lei de Diretrizes e Bases da Educação Nacional em favor de ações afirmativas, sendo a comunidade escolar a maior beneficiada.

Neste trabalho, o professor de História aparece como elemento importante para que se consiga êxito ante as propostas de trabalho com a 
citada lei e seus documentos acessórios de implementação, seja no conhecimento sobre a Lei $10.639 / 03$ ou nas didáticas de ensino a serem utilizadas em sala de aula. Isto nos leva a refletir se há, realmente, formação condizente nos cursos de Licenciatura em História, para ser promovida uma prática eficaz e cada vez mais abrangente.

Pudemos constatar que nas duas grandes universidades cearenses analisadas, UFC e UECE, ainda persiste a necessidade de adequação do Curso de Licenciatura em História da UECE, em seu campus de Fortaleza, mesmo havendo exemplos plausíveis de adequação da grade curricular na formação de historiadores, como os casos da FECLESC E FAFIDAM, à legislação vigente sobre ações afirmativas para os afrodescendentes brasileiros, visando despertar em seus alunos o interesse e valorização nas composições étnicas do Brasil.

Sabemos que ainda há muito a ser feito sobre a aplicação de fato da Lei 10.639/03 no Ensino Superior para a área de História, porém ainda que com os entraves da não existência específica de componentes curriculares específicos, o estudo de Didática apresenta possibilidades de interesses temáticos que podem atuar neste favorecimento, resgatando e abrindo possibilidades de aplicação.

Por fim, para que essas possibilidades sejam concretas, se faz necessária a dedicação do professor de História, tanto o formador, como o que está em formação, visando responsabilidades e atualizações sobre os estudos mais recentes que tocam os desdobramentos da Lei 10.639/03.

\section{Referências}

ALBERTI, Verena. Algumas estratégias para o ensino de história e cultura afro-brasileira. In: PEREIRA, Amilcar Araújo; MONTEIRO, Ana Maria (org.). Ensino de história e culturas afro-brasileiras e indígenas. Rio de Janeiro: Editora Pallas, 2013. p.27-56.

BRASIL. Lei no 9.394, de 20 de dezembro de 1996. Estabelece as Diretrizes e Bases da Educação Nacional. Diário Oficial da União, Brasília, DF, 21 dez. 1996. 
BRASIL. Lei no 10.639, de 9 de janeiro de 2003. Altera a Lei no 9.394, de 20 de dezembro de 1996, que estabelece as Diretrizes e Bases da Educação Nacional, para incluir no currículo oficial da rede de ensino a obrigatoriedade da temática "História e Cultura Afro-Brasileira", e dá outras providências. Brasília: Presidência da República, 2003.

BRASIL. Ministério da Educação. Conselho Nacional de Educação. Resolução no 1, de 17 de junho de 2004. Institui as Diretrizes Curriculares Nacionais para a Educação das Relações Étnico-Raciais e para o Ensino de História e Cultura Afro-Brasileira e Africana. Diário Oficial da União: seção 1, Brasília, p. 11, 22 jun. 2004a.

BRASIL. Ministério da Educação. Conselho Nacional de Educação. Parecer CNE/CP 003/2004. Diretrizes Curriculares Nacionais para a Educação das Relações Étnico-Raciais e para o Ensino de História e Cultura Afro-Brasileira e Africana. Brasília: Ministério da Educação, 2004b

BRASIL. Lei no 11.645, de 10 de março de 2008. Altera a Lei no 9.394, de 20 de dezembro de 1996, modificada pela Lei no 10.639, de 9 de janeiro de 2003, que estabelece as Diretrizes e Bases da Educação Nacional, para incluir no currículo oficial da rede de ensino a obrigatoriedade da temática "História e Cultura Afro-Brasileira e Indígena". Brasília: Presidência da República, 2008.

CANDAU, Vera Maria. O currículo entre o relativismo e o universalismo: dialogando com Jean-Claude Forquin. Revista Educação \& Sociedade, Rio de Janeiro, ano 21, n. 73, p.79-83, dez 2000.

CEARÁ. Conselho Estadual de Educação. Resolução No. 416/2006.

Fortaleza: Governo do Estado do Ceará, 13 dez. 2006.

CÓRDOVA, Fernanda Peixoto; SILVEIRA, Denise Tolfo. Métodos de pesquisa. Porto Alegre: Editora da UFRGS, 2009.

DIALLO, Cíntia Santos. História da África e cultura afro-brasileira no ensino superior público: análises sobre currículos e disciplinas dos cursos de licenciatura em história em Mato Grosso do Sul (2003-2016). Dourados: UFGD, 2017.

FISCHER, Beatriz Terezinha Daudt. Prática docência no ensino superior: questões e alternativas. Revista Educação, Porto Alegre, v. 32, n. 3, p. 311315, set./dez. 2009.

GOMES, Nilma Lino. O movimento negro educador: saberes construídos nas lutas por emancipação. Petrópolis, RJ: Editora Vozes, 2017. 
LIMA, Telma Cristiane Sasso de; MIOTO, Regina Célia Tamaso.

Procedimentos metodológicos na constituição do conhecimento científico: a pesquisa bibliográfica. Revista Katálysis, Florianópolis, v.10, p. 37-45, 2007. Número especial.

MARTINS, Lígia Márcia. Pedagogia histórico-crítica e psicologia históricocultural. In: MARSIGLIA, Ana Carolina Galvão(org.). Pedagogia histórico crítica: 30anos. Campinas, SP: Autores Associados, 2011.p.43-58.

MUNANGA, Kabengele (org.). Superando o racismo nas escolas. 2. ed. rev. Brasília: Ministério da Educação, 2005.

PARREIRAS, Celita. Objetivos educacionais: sua importância para a ação pedagógica. 2017. Disponível em:

http://www.geocities.com/celitaparreiras/. Acesso em: 25 jun. 2017.

PESAVENTO, Sandra Jatahy. História e história cultural. Belo Horizonte: Autêntica, 2003.

SANTOS, Lorene dos. Ensino de história e cultura africana e afro-brasileira: dilemas e desafios da recepção à lei 10.639/03. In: PEREIRA, Amilcar Araújo; MONTEIRO, Ana Maria (org.). Ensino de história e culturas afrobrasileiras e indígenas. Rio de Janeiro: Editora Pallas, 2013. p.57-84.

SAVIANI, Dermeval. Pedagogia histórico-crítica: primeiras aproximações. 8. ed. Campinas: Autores Associados, 2003.

SILVA, Petronilha Beatriz Gonçalves e. Aprendizagem e ensino das africanidades brasileiras. In: MUNANGA, Kabengele (org.). Superando o racismo nas escolas. 2. ed. rev. Brasília: Ministério da Educação, 2005.

SILVA, Petronilha Beatriz Gonçalves e. Ensino de história da África ainda não está nos planos pedagógicos, diz professora. [Entrevista cedida a] Rute Pina. Brasil de fato, São Paulo, 8 jan. 2017. Disponível em:

https://www.brasildefato.com.br/2017/01/08/ensino-de-historia-da-africaainda-nao-esta-nos-planos-pedagogicos-diz-professora/. Acesso em: 20 nov. 2019.

UECE - UNIVERSIDADE ESTADUAL DO CEARÁ. Centro de Humanidades Curso de História. Projeto Político Pedagógico Curso de Licenciatura em História. FECLESC/UECE, 2006.

UECE - UNIVERSIDADE ESTADUAL DO CEARÁ. Histórico da FECLESC. Quixedá, 2018a. Disponível em: http://www.uece.br/feclesc/index.php/historico-da-feclesc. Acesso em: 20 abr. 2018. 
UECE - UNIVERSIDADE ESTADUAL DO CEARÁ. Histórico. Limoeiro do Norte, 2018b. Disponível em:

http://www.uece.br/fafidam/index.php?option=com_content\&view=article\&i $\mathrm{d}=90454 \&$ Itemid $=11 \&$ cssfile=principal.css. Acesso em: 22 abr. 2018.

UFC - UNIVERSIDADE FEDERAL DO CEARÁ. Centro de Humanidades Curso de História. Projeto Político Pedagógico do Curso de História- MODALIDADE LICENCIATURA, 2010.

VEIGA, IIma Passos Alencastro. Organização Didática da Aula: um projeto colaborativo de ação imediata. In: Veiga, Ilma Passos Alencastro (org.).

Aula: gênese, dimensões, princípios e práticas. Campinas: Papiros, 2008. v. 1 , p. 267-298.

Recebido em 26 de setembro de 2018

Aceito em 06 de novembro de 2019 